\title{
Experimental investigation on micromilling of oxygen-free, high-conductivity copper using tungsten carbide, chemistry vapour deposition, and single-crystal diamond micro tools
}

\author{
D Huo $^{1 *}$ and K Cheng ${ }^{2}$ \\ ${ }^{1}$ Product Design and Engineering Department, Middlesex University, London, UK \\ ${ }^{2}$ Advanced Manufacturing and Enterprise Engineering Department, Brunel University, Uxbridge, UK
}

The manuscript was received on 17 September 2009 and was accepted after revision for publication on 9 October 2009.

DOI: $10.1243 / 09544054 J E M 1828 S C$

\begin{abstract}
Insufficient experimental data from various micro tools limit industrial application of the micromilling process. This paper presents an experimental comparative investigation into micromilling of oxygen-free, high-conductivity copper using tungsten carbide (WC), chemistry vapour deposition (CVD) diamond, and single-crystal diamond micromilling tools at a uniform $0.4 \mathrm{~mm}$ diameter. The experiments were carried out on an ultra-precision micromilling machine that features high dynamic accurate performance, so that the dynamic effect of the machine tool itself on the cutting process can be reduced to a minimum. Micromachined surface roughness and burr height were characterized using white light interferometry, a scanning electron microscope (SEM), and a precision surface profiler. The influence of variation of cutting parameters, including cutting speeds, feedrate, and axial depth of cut, on surface roughness and burr formation were analysed. The experimental results show that there exists an optimum feedrate at which best surface roughness can be achieved. Optical quality surface roughness can be achieved with CVD and natural diamond tools by carefully selecting machining conditions, and surface roughness, $R_{a}$, of the order of $10 \mathrm{~nm}$ can also be obtained when using micromilling using WC tools on the precision micromilling machine.
\end{abstract}

Keywords: micromilling, micromachining, OFHC copper, single-crystal diamond tools, tungsten carbide, CVD diamond, micromachinability

\section{INTRODUCTION}

High-accuracy miniature components with dimensions ranging from a few hundred micrometres to a few millimetres, or features ranging from a few to a few hundred micrometres, are increasingly in demand for industries such as electro-optics, automotive, biotechnology, aerospace, medical, and information and communications technology [1-3]. Some miniature or microcomponents require complex, threedimensional (3D) geometries and need to be made from a variety of engineering materials. The materials

*Corresponding author: Product Design and Engineering Department, School of Engineering and Information Sciences, Middlesex University, Bramley Road, London N14 4YZ, UK. email:d.huo@mdx.ac.uk are application-dependent, optical components made from glass, polymer, or aluminium, medical components from polymer or glass, mechanical components from ferrous or non-ferrous metals, and dies/ moulds from copper alloys, aluminium, or highhardness steels [4-12]. In some particular applications, microcomponents and microstructures even require submicrometre accuracy and nanometre surface roughness [13]. It has long been recognized that traditional MEMS manufacturing techniques, such as chemical etching and LIGA, are not suitable for producing true three-dimensional (3D) micro components $[\mathbf{8}, \mathbf{1 4}]$. Mechanical micromachining is, however, an ideal method to produce high-accuracy microcomponents in various engineering materials. Among several mechanical machining processes, micromilling is the most flexible and productive process and 
thus is able to generate a wider variety of complex microcomponents and microstructures at small and medium lot size in particular. Some examples of highaccuracy, micromilled components and microstructures [4-7] are illustrated in Fig. 1.

There are numerous cutting-tool materials being used in conventional machining processes, and the properties of these materials vary in terms of hardness, toughness, wear resistance, etc. However, only a few tool materials have been used for fabricating micromilling tools. Tungsten carbide (WC) is a popular tool material widely used in micromachining processes. There are some micromilling experimental data on using WC tools available in the literature [15-17], but data recommended by tool manufacturers cannot normally be applied to micromilling directly. In addition, some micromilling models based on WC tools have been proposed in the past five years [16-19].

Coated micro tools, i.e. chemistry vapour deposition (CVD) diamond or CBN coatings, are used in some applications to elongate tool life [20]. However, the thickness of the coatings would significantly increase the cutting edge radius by a few micrometres [21] and thus blunt the tool, although this might not be an issue for macro-scale cutting tools. In micromachining, however, the depth of cut is in the range of a few micrometres, and typical features of the microcomponent are in the range of tens to hundreds of micrometres; the well-known size effects will thus play a significant role and change the whole machining process physics. Therefore, increasing the cutting edge radius owing to coatings will negatively affect the micromachining performance [21],

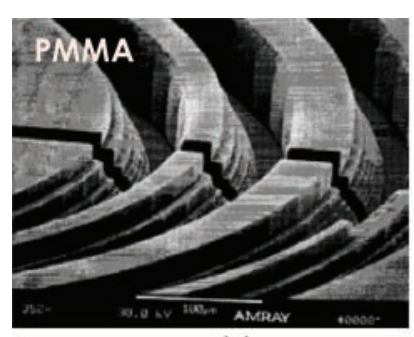

(a)

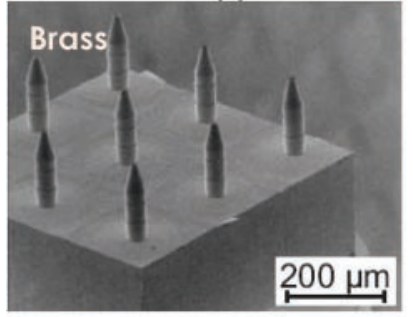

(c)

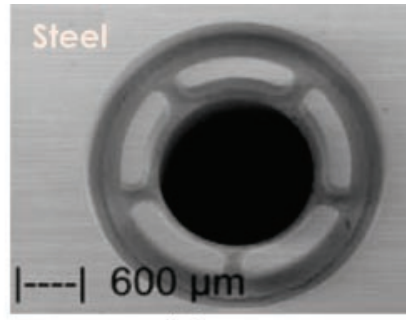

(b)

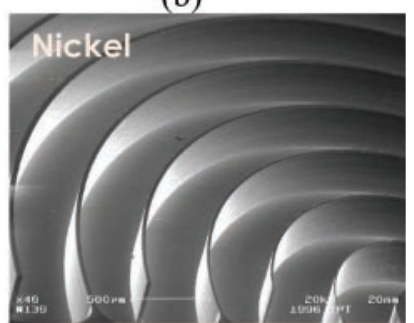

(d)
Fig. 1 Examples of high-accuracy micromilled components and microstructures: (a) micro trenches [4]; (b) micro mould [5]; (c) micro needles array [6]; (d) micro wall [7] although they have a positive effect in terms of wear resistance and low cutting friction. More experimental results are expected to assess the coated microtool performance.

Single-crystal diamond and CVD diamond micromilling tools have been introduced to micromachining in recent years. Single-crystal diamond or CVD diamond micromilling tools have the potential of achieving high-dimensional/form accuracy and an optical surface roughness in various engineering materials, because they not only offer exceptional hardness but also have a submicrometre-level cutting edge radius (typically $1-5 \mu \mathrm{m}$ for WC and coated microtools). Up to now, almost no micromilling data related to single-crystal diamond and CVD diamond microtools have been reported. Insufficient micromilling experimental data are limiting industrial application of micromilling and the understanding of surface and burr formation under various cutting conditions.

Most of the micromilling experiments reported in the literature were performed in miniature machine tools (MMTs) [22-26] or conventional machining centres with retrofitted high-speed spindles $[\mathbf{1 1}, \mathbf{1 5}$, 21], which have limited stiffness or accuracy, and results may not be industrially applicable. Therefore, optimum cutting conditions from various micromilling tools, obtained directly from industrialprecision micromilling machines rather than MMTs and test beds, are desirable for micromachining, so as to bridge the gap.

In this paper, an experimental comparative investigation into micromilling of oxygen-free, highconductivity (OFHC) copper using WC, CVD diamond, and single-crystal diamond milling tools is presented. The experiments were performed on an ultra-precision micromilling machine to minimize the effect of the machine tool itself on the micromachining performance. The influence of variation of cutting parameters, including cutting speeds, feedrate, and depth of cut, on surface roughness and burr formation was analysed.

\section{EXPERIMENTAL SET-UP AND PROCEDURES}

\subsection{Ultra-precision micromilling machine: UltraMill}

Experiments for this work were carried out on a fiveaxis ultra-precision bench-top micromachine, UltraMill, which was developed by the authors at Brunel University (see Fig. 2). The UltraMill is a generalpurpose, ultra-precision micromachine with three linear axes and two rotary axes. The five-axis configuration offers maximum flexibility in tool-workpiece orientation and minimum need for re-set-up, which 
is important to achieve high accuracy on micro parts. Although it is designed for micromachining micro parts, a relatively large machining envelope of $150 \times 150 \times 80 \mathrm{~mm}^{3}$ was specified to enable it to machine large-size components with micro features. The overall footprint is about $1 \mathrm{~m}^{2}$ including the periphery, which is only $10-20$ per cent of that required by conventional ultra-precision machines.

Aerostatic bearings are employed in the machine tool throughout, which differs from most of the ultraprecision machine tools on the market. Three linear slides are driven by ironless, brushless linear motors, and the rotary table is driven by a direct-drive torque motor. In order to improve dynamic stiffness of the aerostatic bearing, a novel squeezed oil film damper is fitted to all slides, and the rotary table in the machine tool developed. Therefore, sub micrometre machining accuracy under dynamic cutting force conditions is guaranteed by the above technologies. The extremely smooth and accurate motion provided by aerostatic bearings, along with diamond tooling, also makes nanometre-range surface roughness on microcomponents possible.

The machine is equipped with a high-speed air bearing spindle that is driven by a DC brushless motor. The spindle developed is $63 \mathrm{~mm}$ in diameter and $115 \mathrm{~mm}$ in length and weighs $2.5 \mathrm{~kg}$, with a $3 \mathrm{~mm}$

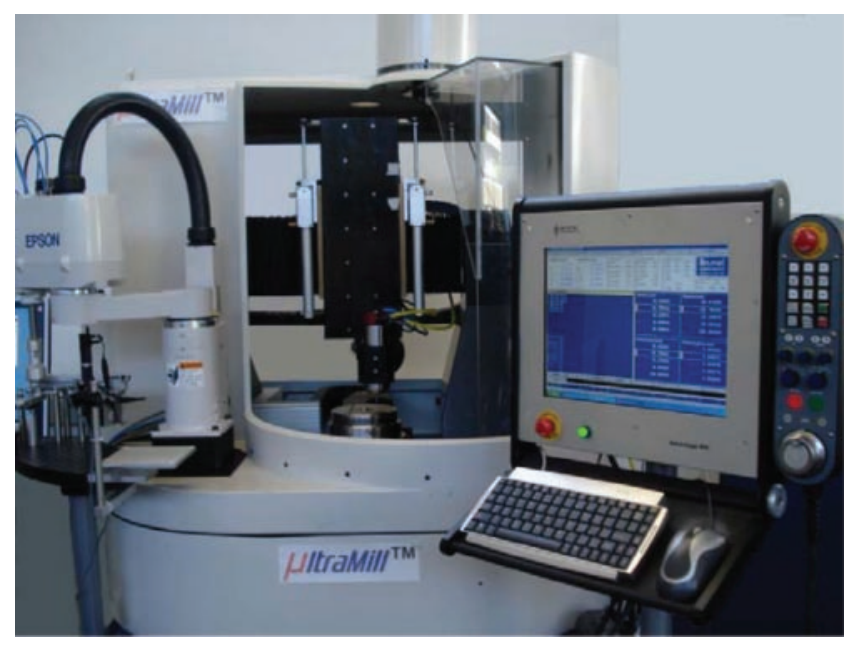

Fig. 2 The UltraMill - ultra-precision micromilling machine: (a) WC; (b) CVD diamond; (c) single-crystal diamond precision four-jawed collet. It has a maximum speed in excess of $200000 \mathrm{r} / \mathrm{min}$, a radial runout of less than $2 \mu \mathrm{m}$, and a radial stiffness of $3 \mathrm{~N} / \mathrm{m}$ measured at the collet end. Bearing friction losses are less than $50 \mathrm{~W}$ at maximum speed, but even so, water cooling is used to minimize thermal distortion [2].

\subsection{Micromilling tools}

The micromilling tools used in the experiments include two-fluted WC end-mills, one-fluted CVD diamond microtools, and one-fluted single-crystal diamond microtools. CVD diamond micromilling tools were fabricated using laser machining, and single-crystal diamond milling tools were fabricated using mechanical grinding and polishing. CVD diamond tools can achieve similar machining quality to that of single-crystal diamond tooling in terms of accuracy and surface finish, and also have the advantage of machining ferrous materials that cannot be processed by single-crystal diamond tooling. Unfortunately, there are almost no CVD and singlecrystal diamond micromilling data available in the literature. All micromilling tools have a nominal diameter of $0.4 \mathrm{~mm}$ and are capable of full immersion slot milling. A uniform tool shank diameter of $3 \mathrm{~mm}$ is used for all micro tools to fit the $3 \mathrm{~mm}$ precision spindle collet. Figure 3 shows the three types of micromilling tool used for the experiments.

\subsection{Procedure and cutting conditions}

The experiments in this work include full immersion slot milling, as illustrated in Fig. 4. For each test, a micro slot $4 \mathrm{~mm}$ long and $0.4 \mathrm{~mm}$ wide was milled along the $y$-direction. OFHC copper was chosen as the workpiece material in this work because it has excellent machinability for both WC and diamond tools, and it is widely used in the optics and mould industries. Before experiments, the top surface of the workpiece was prepared using a $2 \mathrm{~mm}$ end-mill. A small axial depth of cut of $5 \mu \mathrm{m}$ at each pass was used for the surface preparation to eliminate surface damage. A machine vision system (InfiniStix $^{\mathrm{TM}}$ microscope) is integrated into the machine tool, providing $3 \mu \mathrm{m}$ resolution in the $z$-direction to assist in positioning the cutter to the workpiece surface.

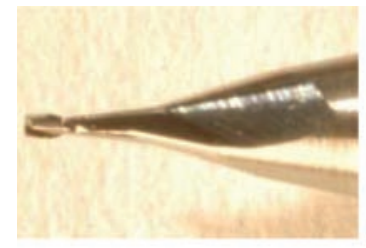

(a)

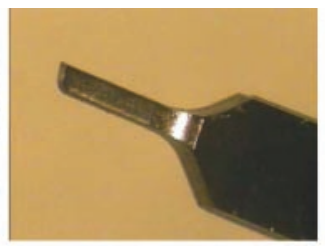

(b)

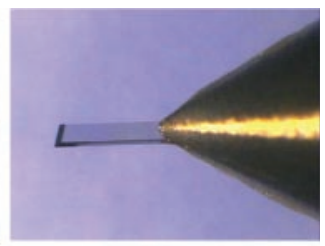

(c)

Fig. 3 Micromilling tools used in the experiments (courtesy of Contour Fine Tooling Limited) 
The feed per tooth $F_{z}$ was varied at $0.1 \mu \mathrm{m}, 0.2 \mu \mathrm{m}$, $0.5 \mu \mathrm{m}, 1 \mu \mathrm{m}, 2 \mu \mathrm{m}, 3 \mu \mathrm{m}$, and $4 \mu \mathrm{m}$, respectively, at a constant axial depth of cut of $30 \mu \mathrm{m}$. The wide range of feedrate was chosen to ensure that minimum chip thickness for all three cutters and workpiece combinations falls into this range, so that the size effect due to the minimum chip thickness can be investigated. The spindle speed $n$ was varied at 10000,30000 , 60000 , and $90000 \mathrm{r} / \mathrm{min}$, respectively, during these experiments. Effect of axial depth of cut $d$ was also studied by varying its value from $10 \mu \mathrm{m}$ to $100 \mu \mathrm{m}$ at intervals of $10 \mu \mathrm{m}$, and fixing the spindle speed at $60000 \mathrm{r} / \mathrm{min}$. Oil-based coolant mist was sprayed onto the cutting zone during all of the micromilling experiments. The aforementioned experiments were

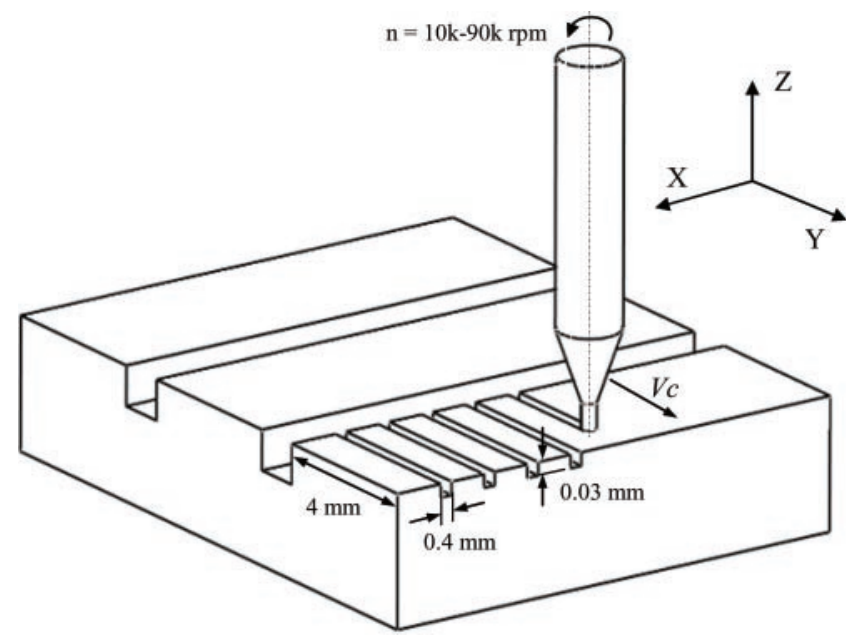

Fig. 4 Schematic diagram of the micromilling experiment repeated on all three types of micro tool. The full experimental matrix is listed in Table 1.

In order to reduce the influence of tool wear on the surface and burr formation, brand new micro tools were used for each set of experiments. An extra slot (experiment 39) was milled at the end of the experiments using the same cutting conditions as for the first slot (see Table 1). This validation slot was then compared with the first slot (experiment 1). For the three types of micro tool, it is observed that there is no significant difference between experiments 1 and 39 in terms of surface roughness, slot width, and burr height. Therefore, the tool wear effect is regarded as negligible for the cutting distance used in this work.

\subsection{Surface roughness and burr height measurement}

The surface roughness of the bottom surface of the micromilled slots was measured using a white light interferometer (Zygo NewView 5000) along the centreline of the slots. To reduce the measurement uncertainty and assess repeatability, five measurements on different areas were conducted for each slot, and an average value of surface roughness $\left(R_{a}\right)$ was used for analysis. There is no standard method of evaluating burr formation. In this research, an average burr height measured across the slot was used quantitatively to assess burr formation. Five measurements of burr height were recorded using a surface profiler (Talysurf Serial-2), and an average value was calculated for discussion.

Table 1 Experimental matrix for micromilling using WC, CVD, and single-crystal diamond milling tools

\begin{tabular}{|c|c|c|c|c|c|c|c|c|c|}
\hline $\begin{array}{l}\text { Experiment } \\
\text { no. }\end{array}$ & $\begin{array}{l}\text { Depth } \\
\text { of cut, } d \\
\text { (mm) }\end{array}$ & $\begin{array}{l}\text { Spindle } \\
\text { speed, } n \\
(\mathrm{r} / \mathrm{min})\end{array}$ & $\begin{array}{l}\text { Cutting } \\
\text { speed, } \\
V_{c}(\mathrm{~m} / \mathrm{min})\end{array}$ & $\begin{array}{l}\text { Feedrate, } \\
F_{z} \\
(\mu \mathrm{m} / \text { flute })\end{array}$ & $\begin{array}{l}\text { Experiment } \\
\text { no. }\end{array}$ & $\begin{array}{l}\text { Depth } \\
\text { of cut, } \\
d \\
(\mathrm{~mm})\end{array}$ & $\begin{array}{l}\text { Spindle } \\
\text { speed, } n \\
(\mathrm{r} / \mathrm{min})\end{array}$ & $\begin{array}{l}\text { Cutting } \\
\text { speed, } \\
V_{c} \quad(\mathrm{~m} / \\
\min )\end{array}$ & $\begin{array}{l}\text { Feedrate, } \\
F_{z} \\
(\mu \mathrm{m} / \text { flute })\end{array}$ \\
\hline 1 & 0.03 & 10000 & 12.56 & 0.1 & 21 & 0.03 & 60000 & 75.36 & 4 \\
\hline 2 & 0.03 & 10000 & 12.56 & 0.2 & 22 & 0.03 & 90000 & 113.04 & 0.1 \\
\hline 3 & 0.03 & 10000 & 12.56 & 0.5 & 23 & 0.03 & 90000 & 113.04 & 0.2 \\
\hline 4 & 0.03 & 10000 & 12.56 & 1 & 24 & 0.03 & 90000 & 113.04 & 0.5 \\
\hline 6 & 0.03 & 10000 & 12.56 & 3 & 26 & 0.03 & 90000 & 113.04 & 2 \\
\hline 7 & 0.03 & 10000 & 12.56 & 4 & 27 & 0.03 & 90000 & 113.04 & 3 \\
\hline 8 & 0.03 & 30000 & 37.68 & 0.1 & 28 & 0.03 & 90000 & 113.04 & 4 \\
\hline 9 & 0.03 & 30000 & 37.68 & 0.2 & 29 & 0.01 & 60000 & 75.36 & 0.5 \\
\hline 10 & 0.03 & 30000 & 37.68 & 0.5 & 30 & 0.02 & 60000 & 75.36 & 0.5 \\
\hline 11 & 0.03 & 30000 & 37.68 & 1 & 31 & 0.03 & 60000 & 75.36 & 0.5 \\
\hline 12 & 0.03 & 30000 & 37.68 & 2 & 32 & 0.04 & 60000 & 75.36 & 0.5 \\
\hline 13 & 0.03 & 30000 & 37.68 & 3 & 33 & 0.05 & 60000 & 75.36 & 0.5 \\
\hline 15 & 0.03 & 60000 & 75.36 & 0.1 & 35 & 0.07 & 60000 & 75.36 & 0.5 \\
\hline 16 & 0.03 & 60000 & 75.36 & 0.2 & 36 & 0.08 & 60000 & 75.36 & 0.5 \\
\hline 17 & 0.03 & 60000 & 75.36 & 0.5 & 37 & 0.09 & 60000 & 75.36 & 0.5 \\
\hline 18 & 0.03 & 60000 & 75.36 & 1 & 38 & 0.1 & 60000 & 75.36 & 0.5 \\
\hline 19 & 0.03 & 60000 & 75.36 & 2 & 39 & 0.03 & 10000 & 12.56 & 0.1 \\
\hline 20 & 0.03 & 60000 & 75.36 & 3 & & & & & \\
\hline
\end{tabular}




\section{RESULTS AND DISCUSSIONS}

This section presents the experimental results and the associated discussions. First, surface roughness results obtained from the three types of micro tool are discussed, followed by the burr formation discussion.

\subsection{Surface roughness}

Figure 5 shows average surface roughness $R_{a}$ as a function of feedrate at various cutting speeds for the three types of micromilling tool. It can be observed from Figs 5(b) and (c) that, for CVD and single-crystal diamond micro tools, the tendency is towards higher roughness values with increases in feedrate when the feedrate is greater than $0.5 \mu \mathrm{m} /$ tooth. However, when the feedrate is smaller than $0.5 \mu \mathrm{m} /$ tooth, the roughness value decreases with increases in feedrate. The smallest surface roughness for single-crystal diamond tools is observed around $11 \mathrm{~nm}$, occurring at $0.2 \mu \mathrm{m} /$ tooth, and a cutting speed of $12.56 \mathrm{~m} / \mathrm{min}$; the smallest surface roughness for CVD diamond tools is observed around $13 \mathrm{~nm}$, occurring at $0.2 \mu \mathrm{m} /$ tooth, and a cutting speed of $37.68 \mathrm{~m} / \mathrm{min}$. The good surface roughness obtained from micromilling using CVD and single-crystal diamond tools indicates that an optical surface roughness can be achieved in micromilling by carefully selecting cutting conditions.

The tendency of surface roughness results for WC tools is towards a lower roughness value with an increase in feedrate, until the feedrate exceeds $3 \mu \mathrm{m} /$ tooth (see Fig. 5(a)), which is different from that of CVD and single-crystal diamond tools. Under the cutting conditions in this work, a surface roughness, $R_{a}$, between 24 and $50 \mathrm{~nm}$ was achieved. The smallest $R_{a}$ value of $24 \mathrm{~nm}$ was observed at a feedrate of $3 \mu \mathrm{m} /$ tooth and a cutting speed of $75.36 \mathrm{~m} / \mathrm{min}$. It should be noted that the surface roughness results and the smallest $R_{a}$ value of $24 \mathrm{~nm}$ achieved in this work are much better than some micromilling data obtained from miniature micromachine tools in the literature. This indicates that the micromilled surface roughness depends, not only on the cutting tools and cutting conditions, but also on the whole machining system, including the motion errors of slideways and spindle runout, etc.

Generally, for all three types of micro tool, spindle speed has no significant effect on the surface roughness. However, for CVD and single-diamond tools, cutting speeds have a negative effect on the surface, i.e. the higher the cutting speed, the higher the surface roughness value, especially for higher cutting speeds (see Figs 5(b) and (c)). By contrast, this trend has not been found in WC micromilling experiments.

When the feed per tooth (i.e. depth of cut) is of the same order as the tool edge radius, the effective rake angle may become negative. Size effects resulting

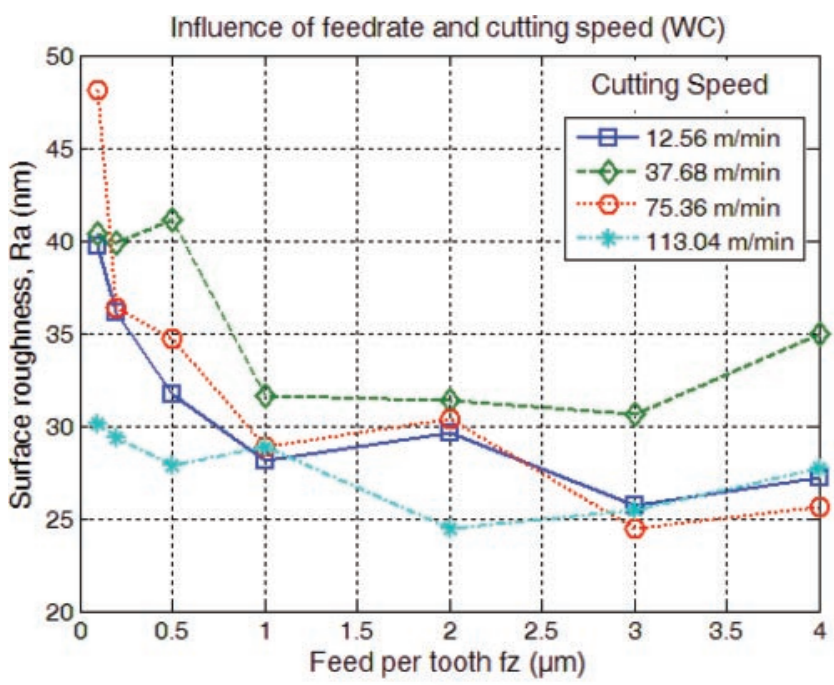

(a)

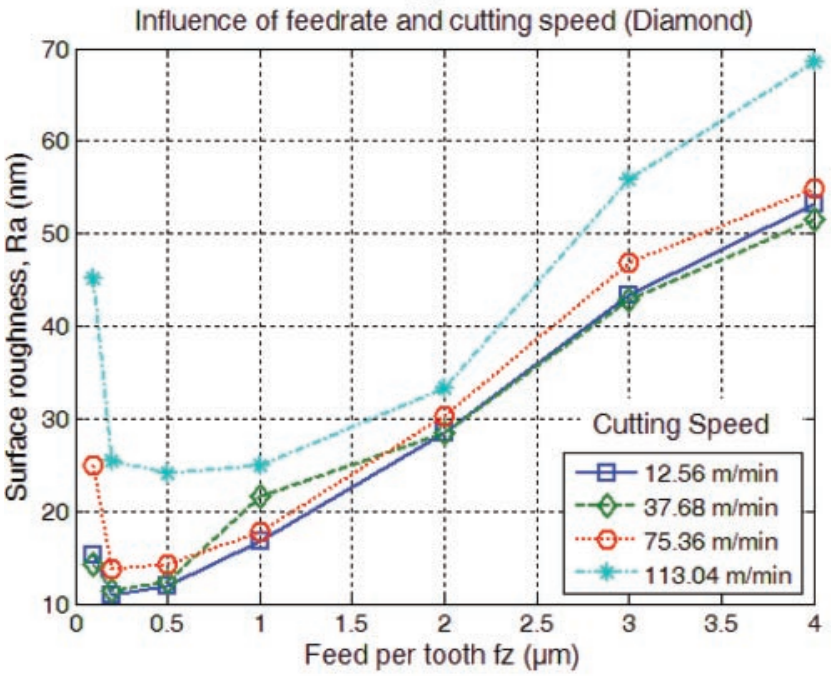

(b)

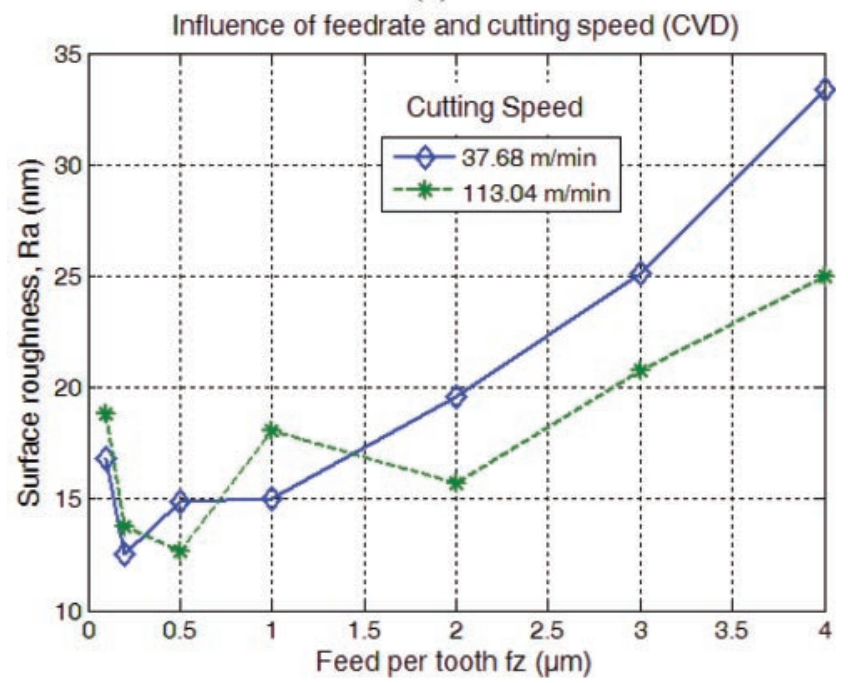

(c)

Fig. 5 Average surface roughness $R_{a}$ as a function of feedrate and cutting speed: (a) WC tool; (b) singlecrystal diamond tool; (c) CVD diamond tool 
from a small ratio of chip thickness to tool edge radius will be a dominant factor for the material removal mechanism and chip generation physics in micromachining. Cutting, ploughing, or slipping phenomena will occur, predominated by this ratio, and will eventually influence machining processes such as surface roughness and burr formation. In previous ultra-precision machining studies, numerous researchers have investigated this size effect, and the critical minimum chip thickness was reported to be around $10-40$ per cent of cutting edge radius [5, 27-30]. WC micro tools used in this work have a cutting edge radius in the range of $3-6 \mu \mathrm{m}$ measured by a scanning election microscope (SEM) for the same batch of micro tools, whereas CVD diamond and single-crystal diamond micro tools have a cutting edge radius of $0.2 \mu \mathrm{m}$ as quoted by the manufacturer. The minimum chip thickness can well be used to explain that there exists an optimum feedrate at which micromilling produces the best surface roughness, as discussed above.

Compared with two-fluted WC micro tools, CVD and single-crystal diamond tools with one sharp cutting edge are prone to instability, because there is always either only one single cutting edge in contact with the workpiece or no contact with the workpiece, which causes periodic variation of the cutting force and poor surface roughness. For diamond micromilling, surface roughness increases sharply with feedrate when the feedrate exceeds $0.5 \mu \mathrm{m} /$ tooth (see Fig. 5(b)), indicating that good surface roughness can only be achieved in diamond micromilling over a limited feedrate range $(0.2-1.0 \mu \mathrm{m} /$ tooth $)$. By contrast, good surface roughness was achieved from a wider feedrate range in the WC micro tools experiments.

Figure 6 shows average surface roughness $R_{a}$ as a function of axial depth of cut. Compared with the effect of feedrate on the surface roughness, there were no substantial differences for all three types of micromilling tool - surface roughness $R_{a}$ increased slightly with axial depth of cut. Under the same feedrate and cutting speed, the $R_{a}$ value for the deepest cut $(100 \mu \mathrm{m})$ was just slightly higher than that for the shallowest cut $(10 \mu \mathrm{m})$. Therefore, using a larger axial depth of cut is an effective way of increasing the machining efficiency, assuming that tool breakage and wear are not issues.

\subsection{Burr formation}

Burrs in micromachining can be categorized in a number of ways. According to their position, burrs can be classified as entrance, exit, top, and bottom burrs. Burrs in micromachining can be classified into four types of burr according to their shape and amount: primary burr, needle-like burr, feathery burr, and minor burr [31]. Sizes of entrance and exit burrs were

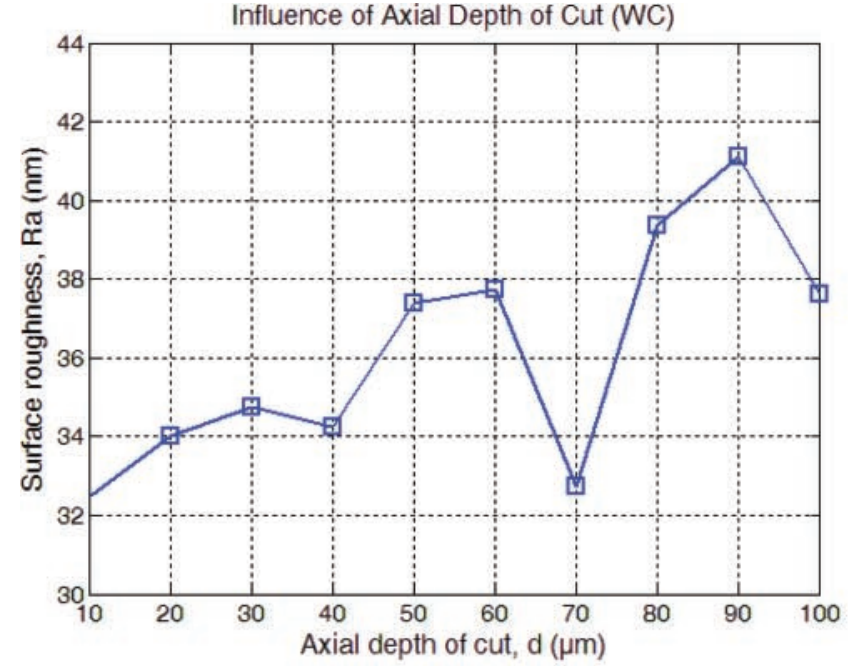

(a)

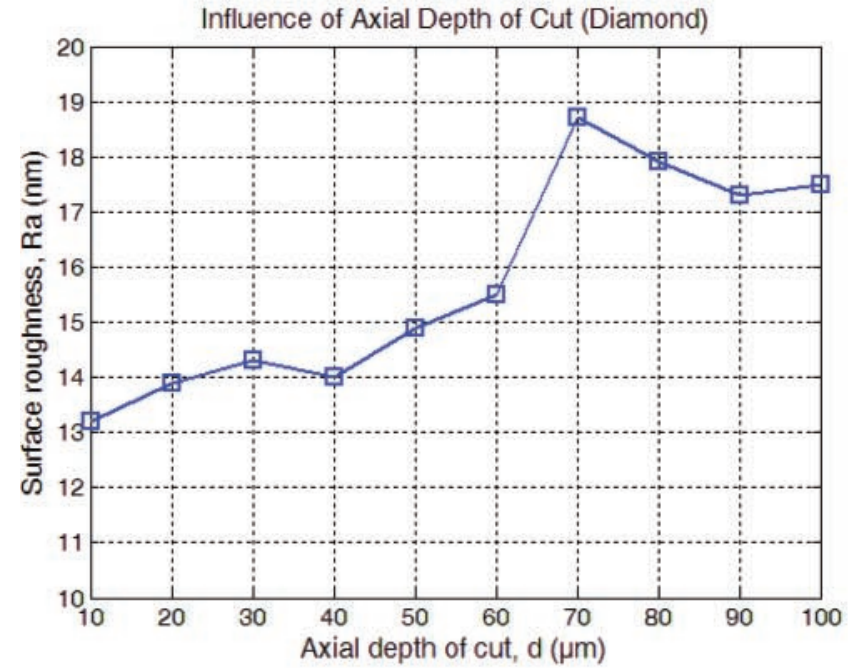

(b)

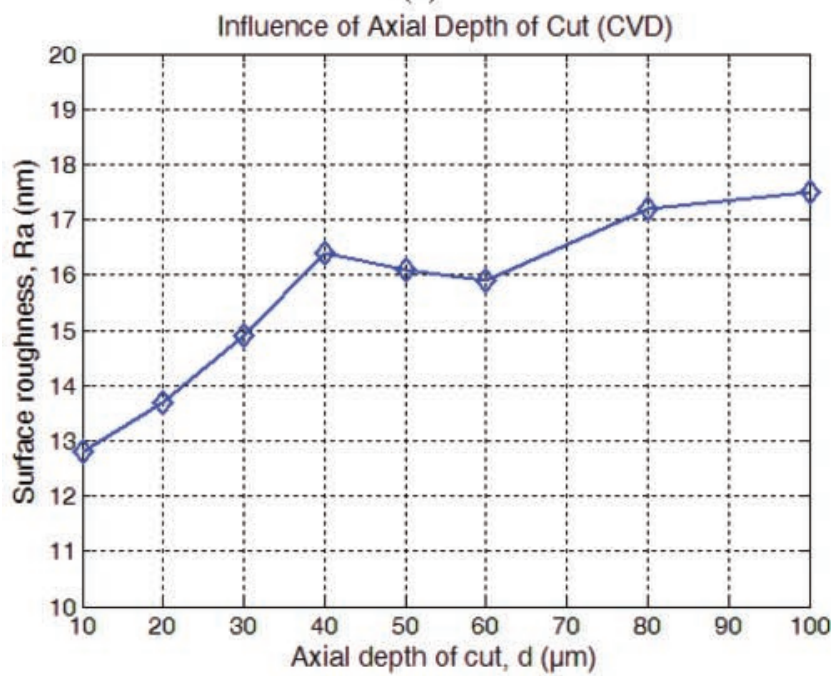

(c)

Fig. 6 Average surface roughness $R_{a}$ as a function of axial depth of cut: (a) WC tool; (b) single-crystal diamond tool; (c) CVD diamond tool 
found to be small, and bottom burrs were ignorable in this work. Top burrs were observed and measured in this work. Because the top burrs in this work were uniform minor burrs, average burr heights measured across the slot were used quantitatively to investigate the relationship between cutting conditions and burr formation. Figure 7 shows some examples of burr formation using diamond and WC cutters.

Burr height at various feedrates and cutting speeds is plotted in Fig. 8, and its variation with axial depth of cut is plotted in Fig. 9. In general, the relationship between burr height and cutting conditions was

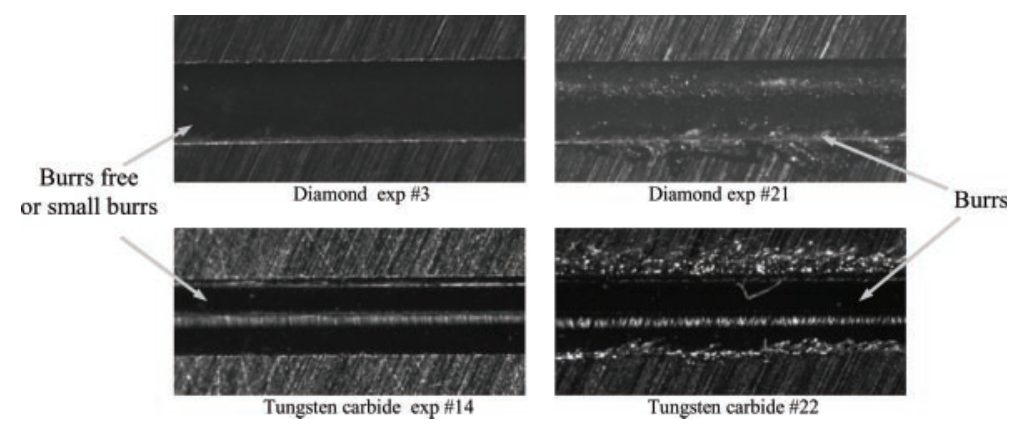

Fig. 7 Examples of burr formation for diamond and WC cutters

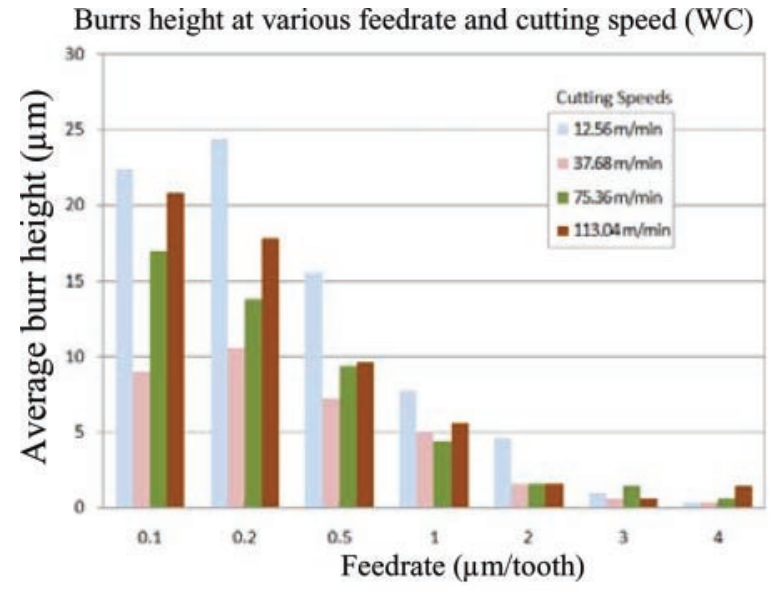

(a) Tungsten carbide

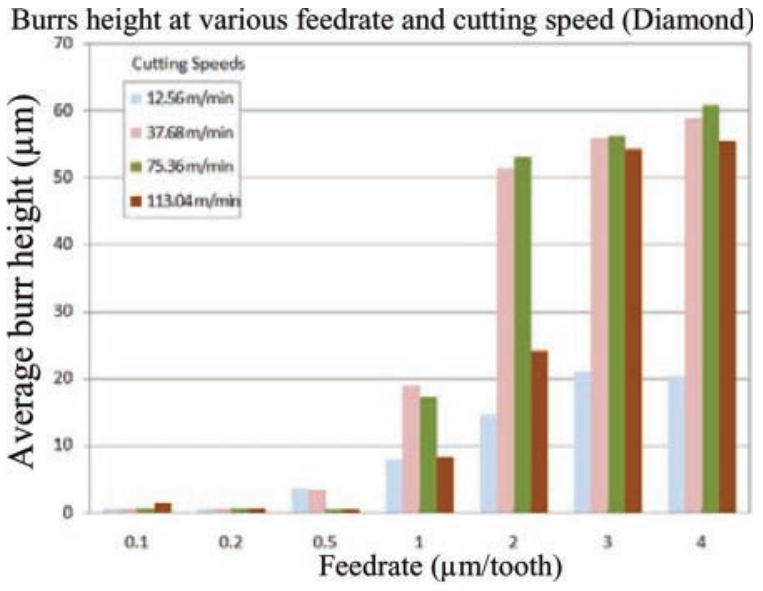

(b) Diamond

Fig. 8 Burr height at various feedrates and cutting speeds: (a) WC; (b) diamond

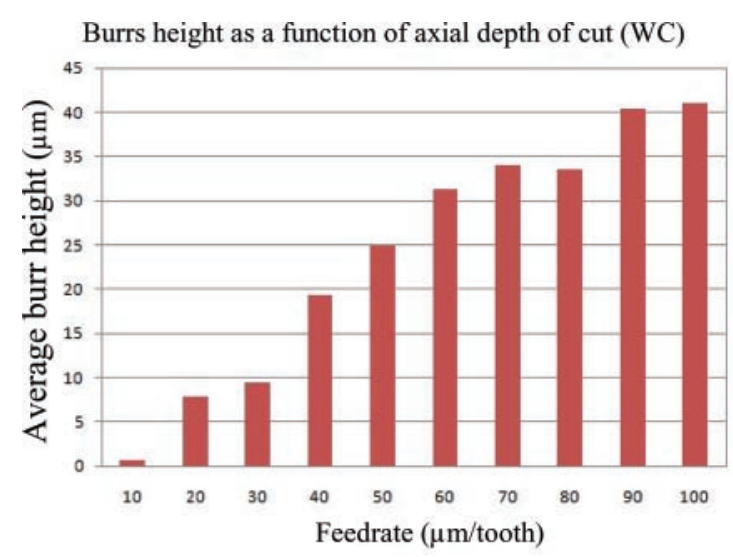

(a) Tungsten carbide

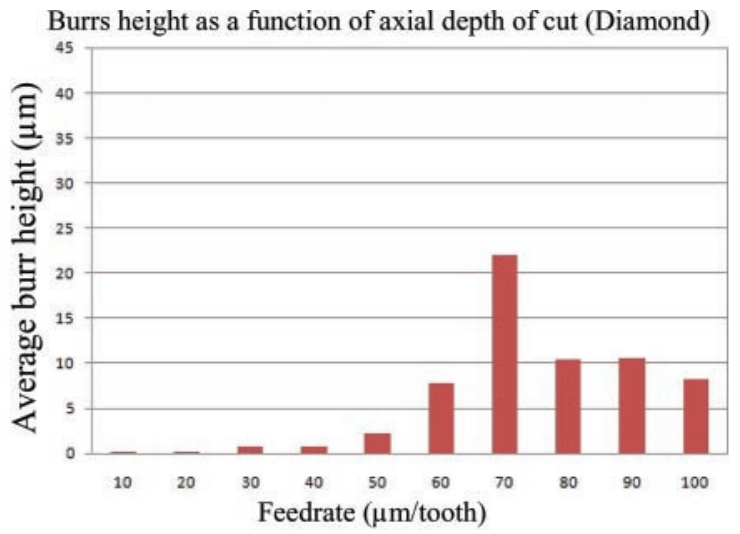

(b) Diamond

Fig. 9 Burr height as a function of axial depth of cut: (a) WC; (b) diamond 
observed to be similar to that between surface roughness and cutting conditions. When the axial depth of cut is $30 \mu \mathrm{m}$, burr-free or small-burr-height $(<5 \mu \mathrm{m})$ cutting was found at a feedrate range of less than $0.5 \mu \mathrm{m} /$ tooth for diamond tools and a feedrate range of 1-4 $\mathrm{m} /$ tooth for WC micro tools, respectively (see Fig. 8). Good surface roughness normally corresponds to small top burr height for both diamond and WC micro tools, which makes cutting parameter optimization less complex. With an increase in the axial depth of cut, for the diamond and WC tools, the burr height tends to increase (see Fig.9). Cutting speed was found to have no significant effect on burr height. However, for WC tools a medium cutting speed $(37.68 \mathrm{~m} / \mathrm{min})$ produces fewest burrs, and for diamond tools a high cutting speed $(113.04 \mathrm{~m} / \mathrm{min})$ helps to reduce burr formation, although more experimental data are needed further to verify this finding.

\section{CONCLUSIONS AND FUTURE WORK}

This paper presents an experimental investigation of micromilling OFHC copper on an ultra-precision micromilling machine. Tungsten carbide, CVD, and single-crystal diamond micro end-mills with $0.4 \mathrm{~mm}$ diameter were used to create full-width slots. Various cutting conditions, including feedrate, spindle speed, and axial depth of cut, were experimentally investigated, particularly in their influence on surface roughness and burr formation. The following major conclusions can be drawn from this work.

1. In micromilling using those three types of cutter, feedrate has a significant influence on surface roughness and burr height, whereas spindle speed has a slight influence on the surface roughness and burr formation. Axial depth of cut has no significant influence on the surface roughness; therefore, using a larger axial depth of cut is an effective way to increase machining efficiency.

2. The existence of the minimum chip thickness dominates the chip and surface formation at a certain feedrate range and determines the optimum feedrate and achievable surface roughness.

3. The micromilling experiments demonstrate that, if $0.4 \mathrm{~mm}$ diameter micro tools are used, the achievable surface roughness $R_{a}$ can reach approximately $10 \mathrm{~nm}$ for CVD and single-crystal diamond micromilling tools and $24 \mathrm{~nm}$ for commercial WC micro tools through careful selection of machining conditions and the use of precision micromilling machines. The experimental results in this work provide practical and industrially feasible micromilling data using CVD and singlecrystal diamond micromilling tools on precision micromilling machines.
Future efforts will be directed towards using wider cutting conditions and systematic modelling of the micromilling process based on more comprehensive cutting trial data.

\section{ACKNOWLEDGEMENTS}

The authors are grateful for the support of the EU 6th Framework NMP Program under contract number NMP2-CT-2-4-500095. Thanks are due to all partners of MASMICRO project consortium and to those within the RTD 5 subgroup in particular for the stimulating meetings and discussions. Thanks are also extended to Contour Fine Tooling Limited for providing the micro end-mills, and Paul Yates, Khalid Nor, and Tao Wu at Brunel University for their assistance in the work.

\section{(C) Authors 2010}

\section{REFERENCES}

1 Ehmann, K. F., Bourell, D., Culpepper, M. L., Hodgson, T. J., Kurfess, T. R., Madou, M., Rajurkar, K., and DeVor, R. E. International assessment of research and development in micromanufacturing, World Technology Evaluation Center, Baltimore, Maryland, 2005.

2 Huo, D., Cheng, K., and Wardle, F. Design of a 5-axis ultraprecision micromilling machine - UltraMill: part 1: holistic design approach, design considerations, specifications. Int. J. Advd Mfg Technol., 2009. DOI: 10.1007/ s00170-009-2128-2.

3 Huo, D., Cheng, K., and Wardle, F. Design of a 5-axis ultraprecision micromilling machine - UltraMill: part 2: integrated dynamic modelling, design optimization and analysis. Int. J. Advd Mfg Technol., 2009. DOI: 10.1007/ s00170-009-2129-1.

4 Friedrich, C. R. and Vasile, M. J. Development of micromilling process for high-aspect-ratio microstructure. J. Microelectromechanical Syst., 1996, 5, 33-38.

5 Weule, H., Hüntrup, V., and Tritschler, H. Microcutting of steel to meet new requirements in miniaturization. Ann. CIRP, 2001, 50(1), 61-64.

6 Takeuchi, Y., Suzukawa, H., Kawai, T., and Sakaida, Y. Creation of ultraprecision microstructures with high aspect ratio. Ann. CIRP, 2006, 56(1), 107-110.

7 Weck, M., Hennig, J., and Hilbing, R. Precision cutting processes for manufacturing of optical components. Proc. SPIE, 2001, 4440, 145-151.

8 Liu, X., DeVor, R. E., Kapoor, S. G., and Ehmann, K. F. The mechanics of machining at the microscale: Assessment of the current state of the science. Trans. ASME, J. Mfg Sci. Engng, 2004, 126(4), 666-678.

9 Brinksmeier, E., Riemer, O., and Stern, R. Machining of precision parts and microstructures. In Proceedings of the 10th International Conference on Precision engineering (ICPE), initiatives of precision engineering at the beginning of a millennium, Yokohama, Japan, 18-20 July 2001, S. 3-11. 
10 Damazo, B. N., Davies, M. A., Dutterer, B. S., and Kennedy, M. D. A summary of micromilling studies. In proceedings of the First International Conference and General Meeting of the European Society of Precision Engineering and Nanotechnology, Bremen, Germany, 31 May-4 June 1999, pp. 322-325.

11 Bissacco, G., Hansen, H. N., and Chiffre, L. D. Micromilling of harded tool steel for mould making applications. J. Mater. Proc. Technol., 2005, 167, 201-207.

12 Huo, D. and Cheng, K. A dynamics-driven approach to precision machines design for micro-manufacturing and its implementation perspectives. Proc. IMechE, Part B: J. Engineering Manufacture, 2008, 222(B1), 1-8. DOI: 10.1243/09544054JEM839.

13 Sweatt, W. C., Gill, D. D., Adams, D. P., Vasile, M. J., and Claudet, A. A. Diamond milling of micro-optics. IEEE A\&E Syst. Mag., 2008, Jan, 13-17.

14 Chae, J., Park, S. S., and Freiheit, T. Investigation of micro-cutting operations. Int. J. Mach. Tools Mf., 2006, 46(3-4), 313-332.

15 Rahman, M., Kumar, A. S., and Prakash, J. R. S. Micromilling of pure copper. J. Mater. Proc. Technol., 2001, 116, 39-43.

16 Vogler, M. P., DeVor, R. E., and Kapoor, S. G. On the modeling and analysis of machining performance in micro-endmilling, Part I: surface generation. Trans. ASME, J. Mfg Sci. Engng, 2004, 126, 685-694.

17 Vogler, M. P., DeVor, R. E., and Kapoor, S. G. On the modeling and analysis of machining performance in micro-endmilling, Part II: cutting force prediction. Trans. ASME, J. Mfg Sci. Engng, 2004, 126, 695-705.

18 Kim, C. J., Mayor, J. R., and Ni, J. A static model of chip formation in microscale milling. Trans. ASME, J. Mfg Sci. Engng, 2004, 126, 710-718.

19 Lai, X., Li, H., Li, C., Lin, Z., and Ni, J. Modelling and analysis of micro scale milling considering size effect, micro cutter edge radius and minimum chip thickness. Int. J. Mach. Tools Mf., 2008, 48, 1-14.

20 Rusnaldy, X., Ko, T. J., and Kim, H. S. Micro-endmilling of single-crystal silicon. Int. J. Mach. Tools Mf., 2007, 47(14), 2111-2119.

21 Torres, C. D., Heaney, P. J., Sumant, A. V., Hamilton, M. A., Carpick, R. W., and Pfefferkorn, F. E.
Analyzing the performance of diamond-coated micro end mills. Int. J. Mach. Tools Mf., 2009, 49(7-8), 599612.

22 Kussul, E., Baidyk, T., Ruiz-Huerta, L., Caballero-Ruiz, A., Velasco, G., and Kasatkina, L. Development of micromachine tool prototypes for microfactories. J. Micromech. Microengng, 2002, 12(6), 795-812.

23 Vogler, M. P., Liu, X., Kapoor, S. G., Devor, R. E., and Ehmann, K. F. Development of meso-scale machine tool (MMT) systems. Society of Manufacturing Engineers, 2002, Paper MS02-181, 1-9.

24 Bang, Y. B., Lee, K. M., and Oh, S. 5-axis micromilling machine for machining micro parts. Int. J. Advd Mfg Technol., 2005, 25, 888-894.

25 Lee, S. W., Mayor, R., and Ni, J. Dynamic analysis of a mesoscale machine tool. Trans. ASME: J. Mfg Sci. Engng, 2006, 128(1), 194-203.

26 Li, H., Lai, X., Li, C., Lin, Z., Miao, J., and Ni, J. Development of meso-scale milling machine tool and its performance analysis. Frontiers Mech. Engng China, 2008, 3(1), 59-65.

27 Filiz, S., Conley, C. M., Wasserman, M. B., and Ozdoganlar, 0. B. An experimental investigation of micro-machinability of copper 101 using tungsten carbide micro-endmills. Int. J. Mach. Tools Mf, 2007, 47(7-8), 1088-1100.

28 Ikawa, N., Shimada, S., and Tanaka, H. Minimum thickness of cut in micromachining. Nanotechnology, 1992, 3, 6-9.

29 Ikawa, N., Donaldson, R. R., Komanduri, R., König, W., Aachen, T. H., McKeown, P. A., Moriwaki, T., and Stowers, I. F. Ultra-precision metal cutting - the past, the present and the future. Ann. CIRP, 1991, 40(2), 587594.

30 Yuan, Z. J., Zhou, M., and Dong, S. Effect of diamond tool sharpness on minimum cutting thickness and cutting surface integrity in ultra-precision machining. J. Mater. Proc. Technol., 1996, 62, 327-330.

31 Chern, G. L., Wu, Y. J. E., Cheng, J. C., and Yao, J. C. Study on burr formation in micro-machining using micro-tools fabricated by micro-EDM. Precis. Engng, 2007, 31, 122-129. 